\author{
Nigel Bark
}

Associate Professor of Clinica Psychiatry, Bronx Psychiatric
The mental health of prisoners in the USA is affected by American history: Dorothea Dix's 1830s campaign; the Civil War and slavery; presidential interventions; the Great Depression; and the introduction of Medicaid and the Affordable Care Act. In 1934, the ratio of prisoners to mental hospital patients was 0.4 ; now, it is $3: 1$, with states varying from 10:1 to 1:1. Those states with the highest ratios also have the highest rates of imprisonment and the lowest expenditures on mental health. Litigation is likely to improve mental health services in prisons and to keep people who are mentally ill out of prisons.

Several strands of American history have contributed to the current mental health status of prisoners in the USA:

- from Dorothea Dix's 1830s campaign to improve the plight of people with severe mental illness by building state hospitals, to deinstitutionalisation without adequate community services

- from slavery and the Civil War, to the invalidation of the Voting Rights Act and racism, with disparity and racial differences persisting

- from a penal culture that promoted rehabilitation (before the 1970s), to one that emphasised mandatory sentencing and punishment, then to a recent realisation that this is inappropriate

- from President Franklin Roosevelt's New Deal with 'the test ... is whether we provide enough for those who have too little', to President Ronald Reagan's 'We're the party that wants to see an America in which people can still get rich' and the rise in the appeal of 'small government'

- from Medicare and Medicaid, introduced in the 1960s, to provide healthcare for people who are elderly, poor or mentally ill, to the Affordable Care Act (ACA) of 2010, which increases Medicaid as well as insurance

- from De Tocqueville's 19th-century observation that 'sooner or later in the United States every controversy ends up in court', to litigation to improve mental health services in prisons

- from the civil rights of those who are mentally ill being largely ignored until the 1960s, when 'civil rights' legislation and case law dangerously limited involuntary hospitalisation, to court-ordered out-patient treatment and mental health courts.

\section{Increasing and unequal prison incarceration}

The USA has the highest rate of incarceration in the world: one of every 100 adults, a $600 \%$ increase in 40 years (Baillargeon et al, 2009; Rich et al, 2011; see also the website of the Bureau of Justice Statistics, http://www.bjs.gov, for statistics here and below). This rate is, though, at last decreasing, as mandatory sentencing laws (introduced during the 'crack' epidemic and a time of rising crime rates) are being repealed (Rich et al, 2011). Black men are disproportionately likely to be in prison: 9\% of all African Americans are behind bars or on probation or parole, compared with only $3.7 \%$ of Hispanics and 2.2\% of Caucasians (Baillargeon et al, 2009). In Michigan, half the prisoners are Black while the population is $14 \%$ Black. African Americans average $23 \%$ of the population in the ten states with the highest rates of incarceration. These include seven of the nine states that were covered by the Voting Rights Act until it was invalidated by the Supreme Court, which will make voting harder for the poor, minorities and people who are mentally ill.

Prisons are where those tried and sentenced to more than a year are housed. Jails are for those arrested, awaiting court appearance or sentenced to less than a year. The states are responsible for prisons and the mental health of prisoners, although some states (such as Louisiana) have private for-profit prisons and some (such as South Carolina) neglect and abuse such prisoners, despite court orders (Cohen, 2014). Jails are administered by cities and counties.

The overall proportion of the population with mental disorders in correctional facilities and hospitals together is about the same as 50 years ago. Then, however, $75 \%$ of that population were in mental hospitals and 25\% incarcerated; now, it is $5 \%$ in mental hospitals and $95 \%$ incarcerated (Gilligan \& Lee, 2013). In 1934, the ratio of prisoners to mental hospital patients was 0.4 (Penrose, 1943); now, it is 3:1, with states varying from 10:1 to 1:1 (Torrey et al, 2010). Those states with the highest ratios - mainly the same states as in 1934, as reported by Penrose (1943) - also have the highest rates of imprisonment (and of murder, gun deaths, poverty and teenage pregnancy - and they vote Republican) and lowest expenditures on mental health (Torrey et al, 2010). The average expenditure on mental health of the ten states with the highest rates of incarceration is $\$ 75$ per person and of the ten with the lowest is $\$ 143$ (according to the Kaiser Family Foundation, http://kff.org). But in the current recession, $\$ 1.6$ billion has been cut 
from state mental health budgets, federal Medicaid (which covers $46 \%$ of state mental health costs) has been reduced (National Alliance on Mental Illness, 2011) and counties, which pay about $16 \%$ of Medicaid costs from property taxes, are also cutting back: Rockland County, where the author lives, has decimated its once model services and has just closed its in-patient unit, which will probably increase the numbers of people with a mental illness in jails.

\section{Prisoners who are mentally ill}

Once incarcerated, half of inmates are found to have a psychiatric disorder and $15-20 \%$ a serious mental illness (Torrey et al, 2010). In the 1930s, only 1.5\% of 9958 prisoners in New York City had a psychosis (Bromberg \& Thompson, 1937). Now, New York City's jail, Riker's Island, with 12000 inmates, has $40 \%$ with a psychiatric diagnosis, and a third of those have major mental illnesses (Gilligan \& Lee, 2013). A recent good diagnostic study found $14 \%$ of males and $31 \%$ of females in jails had a serious mental illness (Steadman et al, 2009), although a meta-analysis of good prison studies found no increase in psychosis (rate about 3.5\%) from 1966 to 2010 but an increase in depression (about 11\%) (Fazel \& Seewald, 2012). Black men have higher rates of serious mental illness and much higher rates of court-ordered out-patient treatment (Swanson et al, 2009). Prisoners with a mental illness are more likely than other prisoners to have: violated prison rules $(58 \%$ v. $43 \%$ ), been assaulted (24\% v. 14\%), been injured in a prison fight $(20 \%$ v. $10 \%)$, been in solitary confinement (American Civil Liberties Union, 2009) and had multiple incarcerations. And they cost more: $\$ 180$ per day against $\$ 80$ per day (Torrey et al, 2010).

In $2011,34 \%$ of state prisoners, $24 \%$ of federal prisoners and $17 \%$ of jail inmates received mental health treatment. In 2000, of the 1558 state public and private adult correctional facilities, 1394 provided mental health services: $70 \%$ screened inmates, $65 \%$ conducted psychiatric assessments, $51 \%$ provided 24 -hour mental healthcare, $71 \%$ provided therapy or counselling, $73 \%$ provided psychotropic medications and $66 \%$ helped released inmates obtain community mental health services.

States vary in the provision of treatment: therapy is provided for $2.7 \%$ to $37 \%$ of prisoners; medication for $1.1 \%$ to $39 \%$. Those states that provide the least are among the ten states with the highest rates of incarceration. In a Michigan study, $17 \%$ of prisoners were receiving treatment $(100 \%$ therapy, $95 \%$ medication), but $65 \%$ of those with a serious diagnosis (13\% of all prisoners) were not being treated (Swanson et al, 2009).

In New York prisons, services consist of 'outpatient' clinics, day programmes, hospital units within the prison and a forensic hospital. In Riker's Island jail, a private company provides the services for New York City and two city hospitals have prison wards. All inmates have a medical examination within 24 hours of admission and a mental health assessment within 72 hours. In Texas, all inmates have an hour-long medical and psychiatric examination, and 20\% are referred for further psychiatric evaluation (Baillargeon et al, 2009).

\section{The law and access to treatment}

Federal laws mandating treatment of prisoners with mental illness apply only to federal prisons. The Eighth Amendment of the US Constitution forbids 'cruel and unusual punishment', which the courts have interpreted as including 'deliberate indifference to serious medical needs' (American Civil Liberties Union, 2009). This has been used to force states (where state law is inadequate) to provide appropriate services: in Massachusetts resulting in a dramatic reduction in rioting, murders, suicides, rape and injuries in prison; in California resulting in a judge having oversight of the treatment of incarcerated people with serious mental illness.

Litigation usually results in 'consent decrees', where the states agree to a set of conditions and the courts monitor them. They are in effect in most states. For example, in Mississippi, where 1000 men were held in solitary confinement in a super-maximum-security unit, a consent decree excluded from that unit all those who had a severe mental illness and introduced mental health workers, which resulted in a $70 \%$ decrease in serious incidents (American Civil Liberties Union, 2009). In New York in response to a law suit (and some tragic deaths) the state agreed to end all solitary confinement for those who were young or pregnant, or who had an intellectual disability or mental illness. Yet in the USA there were still 80000 prisoners (disproportionately mentally ill) in solitary confinement in July 2013.

Another major source of concern and litigation is suicide, which occurs much more in prisons and jails and is the leading cause of death: 41 per year per 100000 inmates in the decade to 2011 (12 per 100000 in the general population).

\section{Diversion from incarceration}

States with high and low rates of imprisonment, recognising that the rights and dignity of people with a mental disorder are compromised, share initiatives aimed at reducing their incarceration. Forty-seven states have police crisis intervention teams that work to avoid the arrest of people who are mentally ill (Aron et al, 2009). Additionally, mental health courts (200 of them, in 43 states) and drug courts (2600) divert the arrested person to psychiatric treatment (Aron et al, 2009). A review of these 'criminal justice liaison and diversion' services found they were beneficial (Scott $e t$ al, 2013). 'Assisted out-patient treatment' (courtordered treatment, usually at hospital or on prison discharge) significantly reduces rates of arrest and incarceration (Torrey et al, 2010) and can halve total costs in the first year (Swanson et al, 2013).

\section{Adverse outcomes}

Released prisoners are 129 times more likely to die from drug overdose and 12 times more likely to 
die from any cause in the first 2 weeks (Rich $e t$ al, 2011). In New York, a charitable organisation helps 1000 offenders with mental illness released from Riker's Island every year. The Affordable Care Act, through a Medicaid mandate, will help released prisoners throughout the country get services (Rich et al, 2011), although many states, mainly the poorest and those with high imprisonment rates, are resisting participation under the Act, aided by attack advertisements paid for by very wealthy outsiders.

\section{Conclusion}

The historical strands, interacting with the tension between federal laws and regulations, states' rights and the Constitution, and enormously variable and highly polarised views, have resulted in great variation in incarceration rates and prisoner mental health across the USA. Overall, there are signs of improvement, with decreasing numbers in prison, but there are still far too many people with mental illness in jail and prison. Litigation and concern for the most vulnerable have helped ensure better treatment in jails and prisons but the high suicide rate shows that it remains inadequate. In this time of economic difficulty, funds for community services are being cut back, which will only increase the incarceration of people who are mentally ill. Psychiatrists and other mental health professionals must give high priority to campaigning to persuade the public and the politicians that it is right and moral to provide appropriate treatment and services for everyone who is mentally ill, irrespective of where they find themselves. Any resulting reduction in imprisonment, hospitalisation and costs is a bonus.

\section{References}

American Civil Liberties Union (ACLU) (2009) Human Rights at Home: Mental IIIness in US Prisons and Jails. Statement for the US Senate Committee on the Judiciary Subcommittee on Human Rights and the Law on 15 September 2009. ACLU.

Aron, L., Honberg, R., Duckworth, K., et al (2009) Grading the States 2009: A Report on America's Health Care System for Adults with Serious Mental Illness. National Alliance on Mental Illness.

Baillargeon, J., Binswager, I. A., Penn, J. V., et al (2009) Psychiatric disorders and repeat incarcerations: the revolving prison door. American Journal of Psychiatry, 166, 103-109.

Bromberg, W. \& Thompson, C. B. (1937) The relation of psychosis, mental defect and personality types to crime. Journal of Criminal Law and Criminology, 28, 70-89.

Cohen, A. (2014) When good people do nothing: the appalling story of South Carolina's prisons. The Atlantic, 10 January.

Fazel, S. \& Seewald, K. (2012) Severe mental illness in 33588 prisoners worldwide: systematic review and meta-regression analysis. British Journal of Psychiatry, 200, 364-373.

Gilligan, J. \& Lee, B. (2013) Report to the New York City Board of Correction, 5 September (available online).

National Alliance on Mental Illness (NAMI) (2011) State Mental Health Cuts: A National Crisis. NAMI.

Penrose, L. S. (1943) A note on the statistical relationship between mental deficiency and crime in the United States. American Journal of Mental Deficiency, 47, 462-466.

Rich, J. D. Wakeman, S. E. \& Dickman, A. B. (2011) Medicine and the epidemic of incarceration in the United States. New England Journal of Medicine, 364, 2081-2083.

Scott, D. A., McGilloway, S., Dempster, M., et al (2013) Effectiveness of criminal justice liaison and diversion services for offenders with mental disorders: a review. Psychiatric Services, 64, 843-849. Steadman, H. J., Osher, F. C., Robbins, P. C., et al (2009) Prevalence of serious mental illness among jail inmates. Psychiatric Services, 60 , 761-765.

Swanson, J. W., Swartz, M., Van Dorn, R. A., et al (2009) Racial disparities in involuntary outpatient commitment. Are they real? Health Affairs, 28, 816-826.

Swanson, J. W., Van Dorn, R. A., Swartz, M. S., et al (2013) The cost of assisted outpatient treatment: can it save states money? American Journal of Psychiatry, 170, 1423-1432.

Torrey, F. T., Kennard, A. D., Eslinger, D., et al (2010) More Mentally IIl Persons Are in Jails and Prisons Than Hospitals: A Survey of the States. Treatment Advocacy Center.

THEMATIC PAPERS

Behavioural and Brain Sciences Unit, Institute of Child Health, London, UK, email d.skuse@ ucl.ac.uk

\title{
Managing the mental health of prisoners: dilemmas and solutions
}

\author{
David Skuse
}

As psychiatrists, we are well aware that all around the world people with serious mental health problems are in prison, where their condition is often unrecognised and untreated. In the UK there have been moves in recent years to provide more mental health support to the prison population. Louis Appleby and colleagues review the success of this initiative, introduced just over a decade ago; he was until recently the national clinical director for offender health. Their analysis points up some significant dilemmas, not least of which is the difficulty prison staff have in differentiating serious mental illness from pervasive but more minor mental disturbance. There clearly needs to be better identification of those most at risk, particularly of suicidal behaviour. 